\title{
Managing Recent-Onset Diabetes: \\ Choosing Durable, Well-Tolerated Therapies and Understanding the Role of Incretin-Based Therapies
}

Jay H. Shubrook Jr, DO

\footnotetext{
This article was prepared

with assistance from

E\&S MedEd Group, Inc.

The author approved the article

and all of its contents.

Financial Disclosures:

Dr Shubrook discloses that he

has received research support

from Sanofi and that he is on

the advisory board for Eli Lilly.

Address correspondence to

Jay H. Shubrook Jr, DO,

Director, Clinical Division,

The Diabetes Institute

at Ohio University,

Grosvenor Hall 320

Athens, $\mathrm{OH} 45701$.
}

E-mail: shubrook@ohio.edu

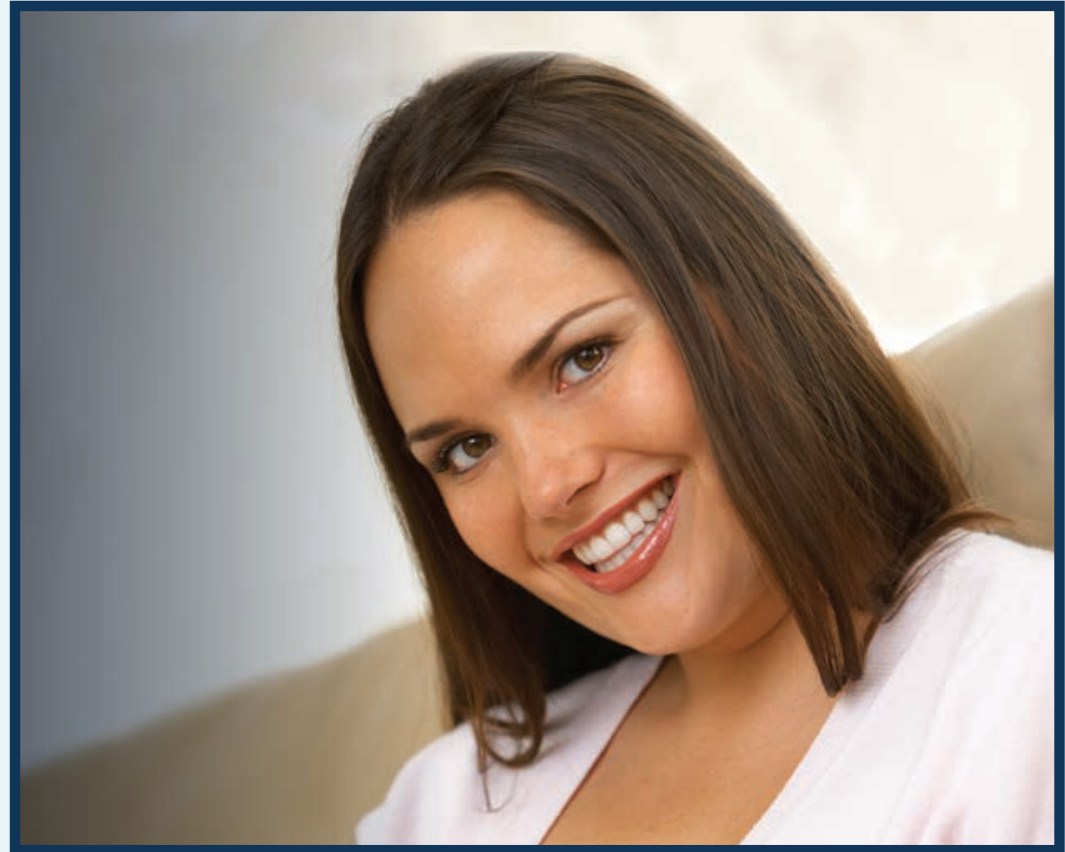

Management of recent-onset diabetes offers osteopathic physicians the opportunity to work with patients to set treatment goals and expectations for this progressive yet manageable disease, as well as intervene early to reduce the risk of diabetesrelated complications. Starting effective therapy early-and intensifying therapy appropriately-to achieve and maintain glycemic goals has been shown to reduce microvascular risks and produce legacy effects that may have macrovascular benefits. Metformin remains a cornerstone of therapy for those patients who can tolerate it. Early combination therapy that is well tolerated reduces risks of hypoglycemia or unwanted weight gain, improves patient adherence, and addresses the multifactoral pathophysiology of even recent-onset diabetes. Incretin-based therapies have been shown to be effective across the spectrum of type 2 diabetes mellitus, including recent-onset diabetes. The present article reviews the use of incretin-based therapies early in the disease process of type 2 diabetes mellitus.

J Am Osteopath Assoc. 2014;114(5 suppl 2):S6-S13

doi:10.7556/jaoa. 2014.088

This supplement is supported by an independent educational grant from Novo Nordisk Inc. 
A s changing lifestyles lead to less physical activity and higher rates of obesity, diabetes mellitus remains among the most common chronic diseases in the United States and continues to increase in prevalence. Data from the 2011 National Diabetes Fact Sheet indicate that 25.8 million children and adults in the United States- $8.3 \%$ of the population-have diabetes. ${ }^{1}$ A total of 1.9 million new cases of diabetes were diagnosed in people aged 20 years or older in $2010 .^{1}$

Type 2 diabetes mellitus (T2DM) is an important contributor to premature vascular disease, blindness, renal failure, and lower-limb amputations. In the United States, 79 million people (approximately 1 in 3 US adults aged $\geqslant 20$ years) have prediabetes, a condition in which blood glucose or glycated hemoglobin $\mathrm{A}_{1 \mathrm{c}}\left(\mathrm{HbA}_{1 \mathrm{c}}\right)$ levels are higher than normal but not high enough to be classified as diabetes (ie, $\mathrm{HbA}_{1 \mathrm{c}} 5.7 \%-6.4 \%$ ). ${ }^{1}$

\section{Etiologic Process of} and $\beta$-Cell Dysfunction in T2DM

Primary predisposing factors for T2DM include genetic features of insulin resistance and insulin secretory defects. Secondary precipitating factors include obesity, low levels of physical activity, advancing age, smoking, and sleep disturbance. Finally, glucotoxicity and lipid toxicity can accelerate this pathophysiologic process. ${ }^{2}$ Insulin resistance (occurring in the muscle and liver) and $\beta$-cell dysfunction are key pathophysiologic defects of T2DM and have been well recognized for decades.
Type 2 diabetes mellitus is frequently asymptomatic and remains undiagnosed for many years - as many as one-third of individuals with diabetes are unaware that they have the disease. ${ }^{1}$ The average time from development of T2DM to clinical presentation is 4 to 7 years. ${ }^{3} \beta$-Cell dysfunction occurs early in the course of diabetes, and in reality, it is well progressed in the impaired glucose tolerance state. Persons in the upper tertile of this state are maximally or near-maximally insulin resistant and may lose over $80 \%$ of their $\beta$-cell function before their diabetes is recognized. ${ }^{4}$ T2DM does not occur in the absence of progressive $\beta$-cell failure. Thus, therapeutic agents that do not adversely affect $\beta$-cell function or that may improve $\beta$-cell function may slow disease progression. There is some evidence of possible deleterious effects of sulfonylureas on $\beta$-cell function, ${ }^{5}$ which may explain the lower "durability" of their antihyperglycemic effects as evidenced in the A Diabetes Outcome Progression Trial. ${ }^{6}$

Other factors also play a role in glucose intolerance in patients with T2DM, including accelerated lipolysis (lipotoxicity, increased free fatty acids), incretin deficiency or resistance in the gastrointestinal tract, insulin resistance in the brain, and impaired glucose transport in the kidneys. ${ }^{4}$ These multiple pathophysiologic defects require use of agents with different mechanisms of action to successfully manage T2DM. ${ }^{7}$ Combination therapy that includes nutrition, physical activity, agents that affect insulin sensitivity (eg, metformin), and agents that address other aspects of diabetes pathophysiology represents a more comprehensive paradigm in the management of this complicated progressive disease. Indeed, the multifactoral nature of hyperglycemia in T2DM dictates the need for therapies using multiple mechanisms of action (Figure 1). ${ }^{4}$

\section{Rationale for Addressing Hyperglycemia}

The complications of T2DM begin early in the progression from normal glucose tolerance to frank diabetes. In fact, many patients present with evidence of diabetic complications at the time of diagnosis. For example, up to $21 \%$ of patients with T2DM have retinopathy when their disease is first diagnosed..$^{8}$ Most, if not all, diabetic complications progressively worsen as glycemic control worsens.

The historic rationale for improving hyperglycemia in patients with T2DM has been reduction of microvascular risk. As shown in the United Kingdom Prospective Diabetes Study, an estimated $37 \%$ decrease in microvascular risk is achieved for each $1 \%$ decrement in $\mathrm{HbA}_{1 \mathrm{c}}$ level (Figure 2). ${ }^{9}$ The decrease in macrovascular risk (ie, myocardial infarction risk) was estimated at $14 \%$ for each $1 \%$ decrease in $\mathrm{HbA}_{1 \mathrm{c}}$ level in the same landmark trial $(P<.0001){ }^{9}$

The United Kingdom Prospective Diabetes Study, conducted with T2DM patients, and the Diabetes Chronic Complications Trial, which studied patients with type 1 diabetes mellitus, are the 2 landmark trials that convincingly demonstrated that tight glycemic control has beneficial effects on microvascular end points. These studies also revealed a "legacy effect," which is a 


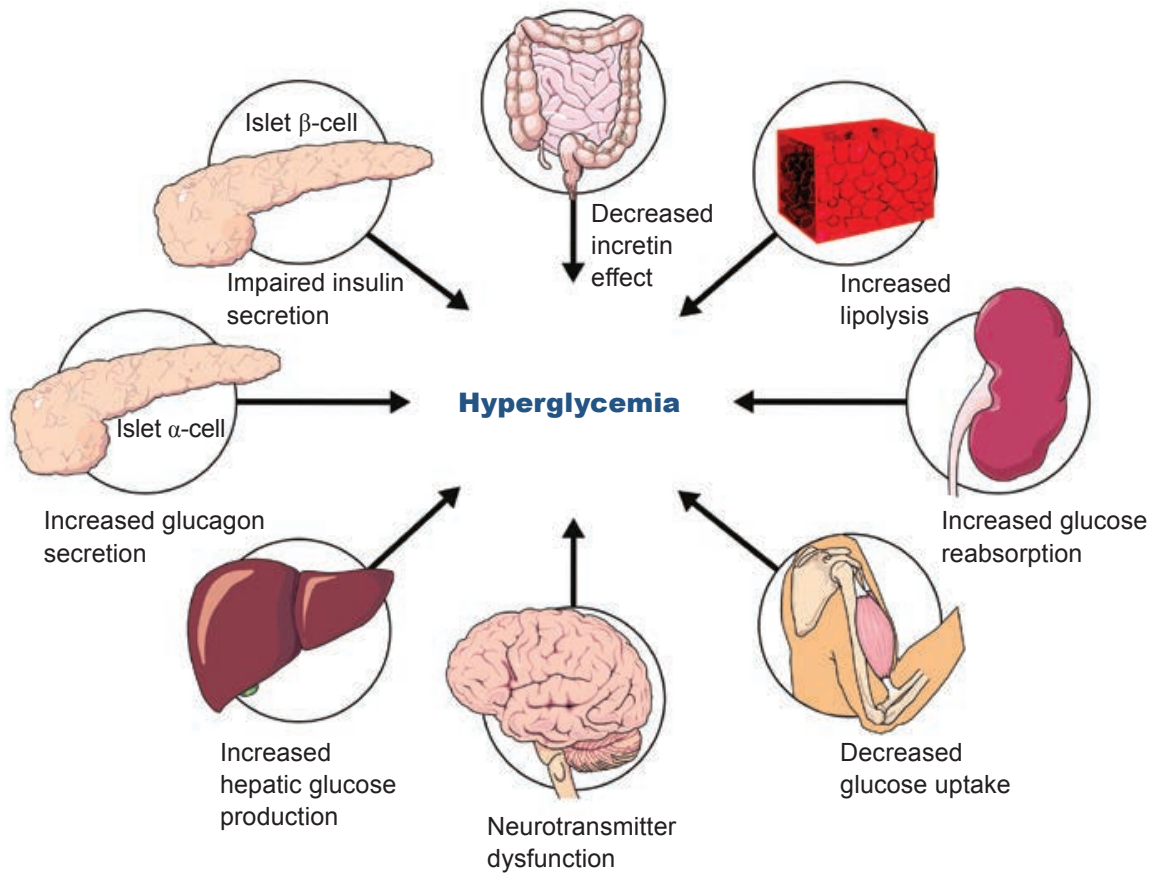

Figure 1.

Multifactoral nature of hyperglycemia in patients with type 2 diabetes mellitus requires multiple mechanisms of action. ${ }^{4}$ Source: Diabetes: a journal of the American Diabetes Association by American Diabetes Association; Stanford University. Reproduced with permission of the American Diabetes Association in the format Continuing Education via Copyright Clearance Center.

sustained benefit with respect to cardiovascular disease outcomes seen long after the conclusion of the trial, demonstrating benefits of early treatment on long-term outcomes. ${ }^{10,11}$ Even 10 years after an intensive glucose-control intervention ended, patients benefited from previous therapy. ${ }^{10,11}$

\section{Importance of Early Pharmacotherapy}

Initiating metformin soon after diabetes diagnosis and while a patient's $\mathrm{HbA}_{1 \mathrm{c}}$ level is low may preserve $\beta$-cell function, prolong the effectiveness of metformin, reduce lifetime glycemic burden, and prevent diabetes complications. Waiting to start therapy reduced the antihyperglycemic efficacy of metformin- therapy started soon after diagnosis of T2DM vs 3 months later worked twice as long. Beginning treatment in patients with lower $\mathrm{HbA}_{1 \mathrm{c}}$ levels (ie, in less glucotoxic patients) also was associated with greater durability of drug effect. ${ }^{12}$ These findings support the current treatment algorithm for hyperglycemia management that recommends metformin initiation for most patients when diabetes is first diagnosed. ${ }^{13}$

Although metformin is a cornerstone drug for managing T2DM, it is contraindicated in persons with any condition that could increase the risk of lactic acidosis, including kidney disorders (creatinine levels $>1.7 \mathrm{mg} / \mathrm{dL}$, although this is an arbitrary limit), lung disease (such as chronic obstructive pulmonary disease), and liver disease. ${ }^{14}$ Severe gas- trointestinal distress may also preclude patient adherence and may require careful dose adjustment or the use of extended-release formulations (which are more expensive than generic immediate-release forms).

Metformin monotherapy will fail over time in its ability to help patients maintain glycemic control. However, glyburide (a sulfonylurea) had the fastest rates of secondary failure compared with metformin and rosiglitazone (a thiazolidinedione [TZD]), with rosiglitazone having the lowest rates among these 3 oral agents (Figure 3 ). ${ }^{6}$ (Secondary failure is the deterioration of glucose control in patients with T2DM on oral antidiabetic drugs and is primarily due to the progressive decline in $\beta$-cell function and reduction in insulin secretion.)

\section{Individualizing Glycemic Targets}

Glycemic goals should be individualized for each patient. In patients with recent-onset diabetes who do not have substantial or burdensome complications, the goal of therapy should be to reduce the risk of future complications. Tighter glucose goals (closer to normal levels, ie, $\mathrm{HbA}_{1 \mathrm{c}}$ levels closer to $6 \%$ if achievable without undue risk of hypoglycemia) may be appropriate. ${ }^{15}$ The American Association of Clinical Endocrinologists (AACE) recommends a general $\mathrm{HbA}_{1 \mathrm{c}}$ target of $\leqslant 6.5 \%$, which might be a reasonable goal for patients with recent-onset diabetes who are relatively healthy, at low risk for hypoglycemia, and without concurrent illness. ${ }^{14}$ 
Hypoglycemia has been a limiting factor in achieving $\mathrm{HbA}_{1 \mathrm{c}}$ targets in the past, when the common additions to metformin therapy, other than TZDs, were primarily limited to insulin and sulfonylureas. ${ }^{16}$

\section{Pharmacologic \\ Treatment of T2DM: From Monotherapy to Dual Therapy}

The basic tenets of treatment of patients with T2DM are that it should be (1) based on known pathophysiologic abnormalities, (2) adjusted according to unique patient characteristics, and (3) comprehensive in nature (ie, not glucose- or $\mathrm{HbA}_{1 \mathrm{c}}$-centric). Most patients will require glucose-lowering therapy with agents that have complementary and synergistic mechanisms of action. They will also likely require attention to cardiovascular risk factor reduction. The key point is that treatment that addresses the progressive nature of T2DM early in the disease course will reduce the likelihood of poor outcomes for patients.

When a primary goal is to avoid hypoglycemia, the American Diabetes Association and the European Association for the Study of Diabetes provide a modification of their treatment algorithm, suggesting 2-drug combinations that include metformin and either a TZD, a dipeptidyl peptidase-4 (DPP-4) inhibitor, or a glucagon-like peptide-1 (GLP-1) receptor agonist (Figure 4). ${ }^{13}$ This algorithm acknowledges the use of agents in addition to metformin that work in glucose-dependent ways - that is, only in the presence of hyperglycemia. One might also now include the so- dium glucose cotransporter-2 (SGLT-2) inhibitors, which were not approved at the time of the consensus statement but are also associated with a low risk of hypoglycemia. ${ }^{17}$

For patients who are overweight or obese, drug-induced weight gain may be problematic or may adversely affect treatment adherence. ${ }^{22}$ Here, the American Diabetes Association and the European Association for the Study of Diabetes treatment algorithm also offers a variation on their overall algorithm for 2-drug therapy (Figure 5), ${ }^{13}$ which is the addition of either DPP-4 inhibitors (which are weight neutral; they do not cause weight gain), or GLP-1 receptor agonists (which are often, though not always, associated with some weight loss). ${ }^{18}$ (The weight loss effects of GLP1 receptor agonists occur independent of glucose lowering. ${ }^{18}$ ) Although treatments generally should not be chosen solely on drug acquisition costs, it may be necessary, especially for lowerincome groups in which drug costs may adversely affect adherence rates. ${ }^{18}$ If this barrier cannot be overcome through free clinics, industry patientassistance programs, or insurance disease management programs, then sulfonylureas may be considered. ${ }^{13}$

The 2013 American Association of Clinical Endocrinologists comprehensive diabetes control algorithm provides suggestions for dual therapy beyond metformin (or other first-line agents) that include "ratings" (eg, "few adverse events or possible benefits," "use with caution") and consideration of more of the available classes of drug therapy (ie, insulin, TZDs, SGLT-2 inhibitors, co-

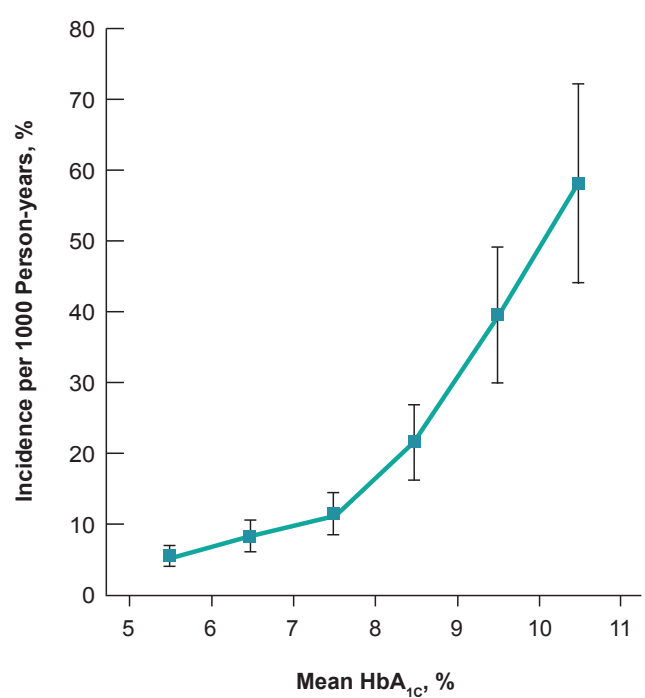

Figure 2.

Incidence of microvascular disease by glycated hemoglobin $\mathrm{A}_{1 \mathrm{c}}\left(\mathrm{HbA}_{1 \mathrm{c}}\right)$ level. There was an estimated $37 \%$ decrease in microvascular risk for each $1 \%$ decrement in $\mathrm{HbA}_{1 \mathrm{c}}(P<.0001)$. This microvascular risk reduction supports the rationale for improving glycemia. Source: Reproduced from Stratton IM, Adler Al, Neil HA, et al. Association of glycaemia with macrovascular and microvascular complications of type 2 diabetes (UKPDS 35): prospective observational study. BMJ. 2000;321(7258):405-412, ${ }^{9}$ with permission from BMJ Publishing Group Ltd.

lesevelam, bromocriptine quick release, $\alpha$-glucosidase inhibitors, and glinides). ${ }^{14}$

Note that if glycemic goals are not met within 3 months of an adequate trial of therapy (adequate dose titration), the algorithm recommends intensification of therapy. ${ }^{14}$ Clinical inertia, in the form of not addressing failure to achieve goals for various reasons (holiday eating, vacations, promises of renewed lifestyle intervention) exposes patients to glycemic burden and an increased risk of diabetes-related complications. 


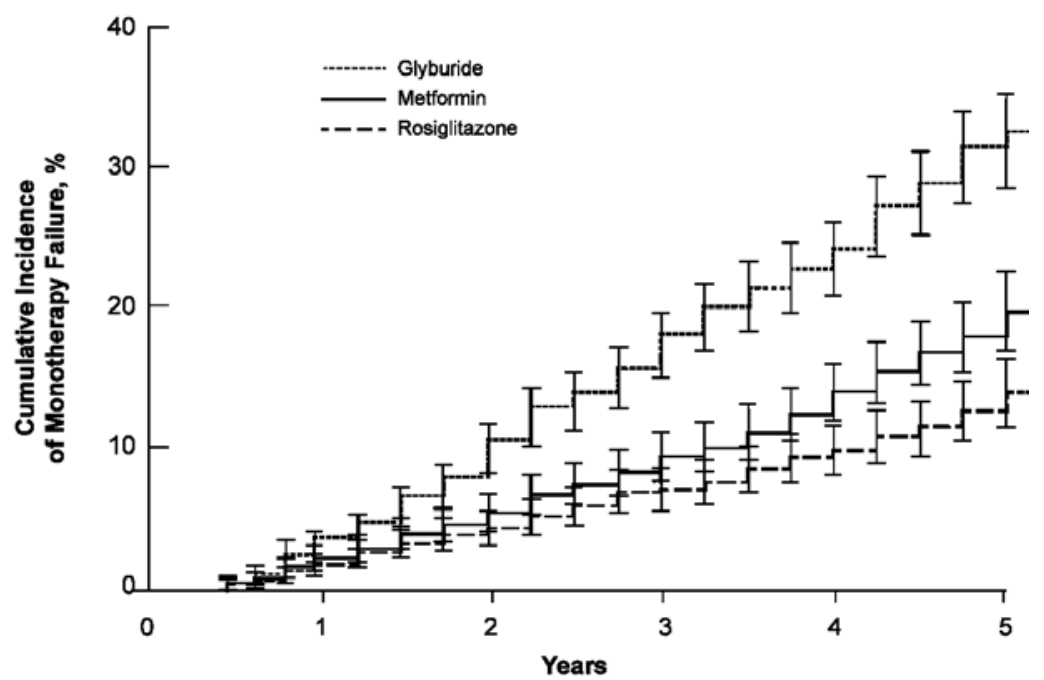

Treatment

Rosiglitazone

Metformin

Glyburide

1393

1337

$\begin{array}{rr}1207 & 1078 \\ 1205 & 1076 \\ 1114 & 9\end{array}$

No. at Risk

Figure 3.

Cumulative incidence of monotherapy failure of 5 years. ${ }^{6}$ Hazard ratios (95\% confidence intervals) were as follows: rosiglitazone vs metformin, $0.68(0.55-0.85)(P<.001)$; rosiglitazone vs glyburide, $0.37(0.30-0.45)$

$(P<.001)$. Source: The New England Journal of Medicine by the Massachusetts Medical Society. Reproduced with permission of the Massachusetts Medical Society, in the format reuse in CME materials via Copyright Clearance Center.

\section{Rationale for Use of Incretin-Based Therapies in Early-Onset T2DM}

Short-term studies have shown that incretin hormones and incretin-based therapies (ie, DPP-4 inhibitors and GLP-1 receptor agonists) protect $\beta$ cells by enhancing $\beta$-cell proliferation and differentiation as well as by inhibiting $\beta$-cell death. ${ }^{19}$ They also stimulate $\beta$-cell function by recruiting $\beta$ cells to the secretory process and increasing insulin biosynthesis and secretion. Therefore, incretin-based therapies might alter disease progression if used as an early intervention when there is still enough $\beta$-cell mass and function available to be preserved. ${ }^{19-21}$ Whether this effect will be confirmed by long-term clinical data remains to be seen. However, as other therapies (with the possible exception of TZDs) do not have positive effects on $\beta$-cell function, these findings support the use of incretin-based therapies early in the course of T2DM. Furthermore, though not an approved use, incretin therapy has been shown to provide value in patients with prediabetes, impaired glucose state, and impaired fasting glucose. ${ }^{19}$

\section{Use of Incretin-Based Therapies as Monotherapy}

Metformin is considered the preferred first-line treatment for most patients with T2DM except those for whom it is contraindicated or for those unable to tolerate it. Because of a lack of extensive clinical trial data and clinical experience, clinical guidelines have yet to adopt incretin-based therapies as first-line therapy for newly diagnosed patients with T2DM except for those who are unable to use metformin. There are clinical trial data, however, supporting the use of either DPP-4 inhibitors or GLP-1 receptor agonists as monotherapy in drug-naïve T2DM patients. Specifically, various doses of sitagliptin given in patients whose diabetes is not controlled by lifestyle intervention alone showed dose-dependent decreases in $\mathrm{HbA}_{10}$ levels ranging from $-0.15 \%$ to $-0.76 \%$ (dose ranges were $5 \mathrm{mg}$ twice daily to 200 mg every day; approved dosing for patients without renal impairment is $10-20 \mathrm{mg}$ every day). ${ }^{22-25}$ Saxagliptin used as monotherapy (doses $2.5 \mathrm{mg}$ to $100 \mathrm{mg}$ [approved doses are 2.5 to $5 \mathrm{mg}$ daily]) are associated with $\mathrm{HbA}_{10}$ reductions of $-0.43 \%$ to $-1.09 \%$ compared with placebo. ${ }^{26,27}$ Glucagon-like peptide-1 receptor agonists have the added benefit of being especially useful early in the disease process for patients who are overweight or obese ${ }^{28-43}$ while providing more robust glucose-lowering results than the DPP-4 inhibitors. ${ }^{14}$ These receptor agonists are given by subcutaneous injection, whereas DPP. 4 inhibitors are given orally, which may affect aspects of patient education and patient training. Also, GLP-1 receptor 


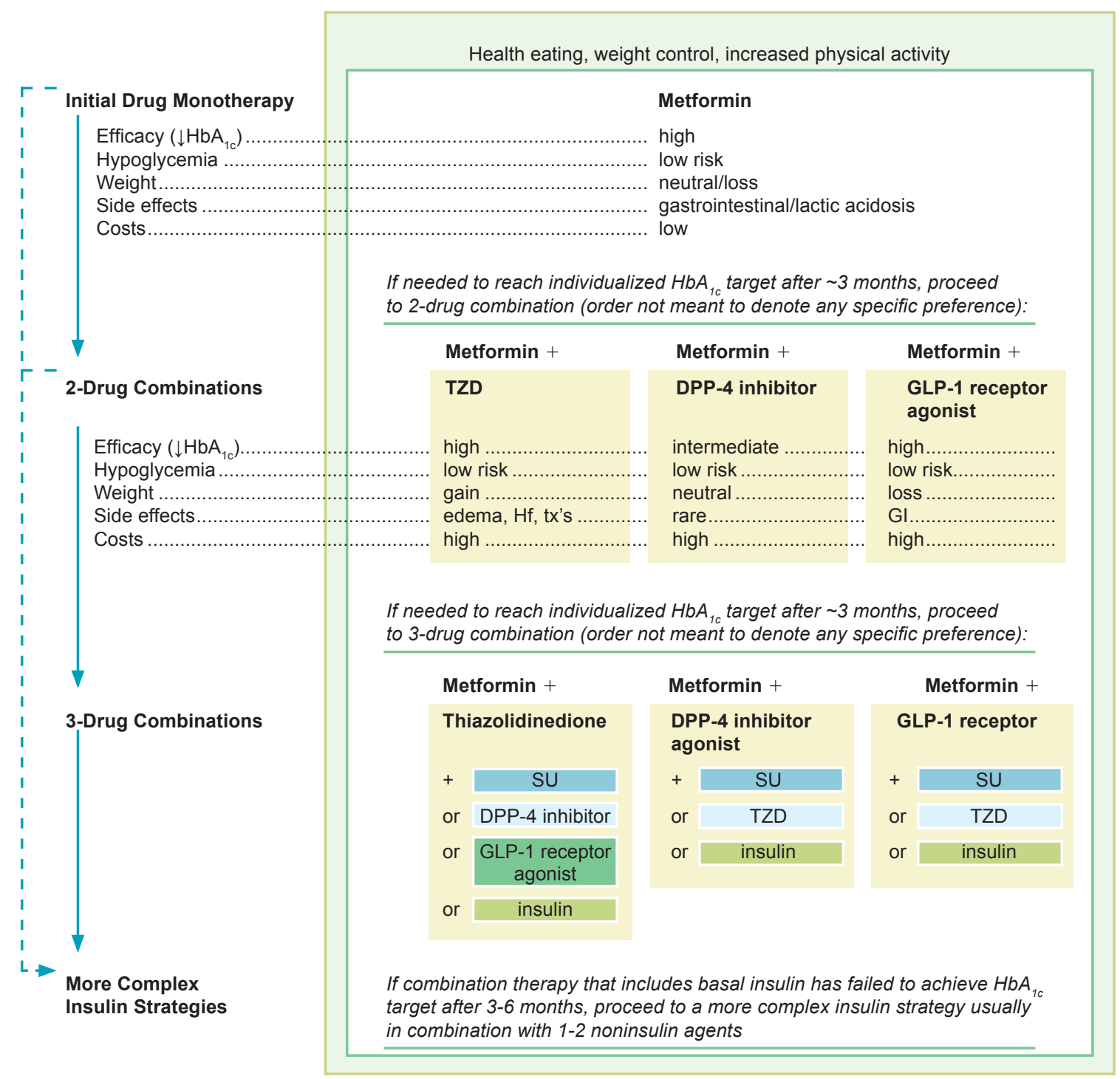

Figure 4.

Algorithm for patients when the goal is to avoid hypoglycemia. ${ }^{13}$ Source: Diabetes: a journal of the American Diabetes Association by American Diabetes Association; Stanford University. Reproduced with permission of the American Diabetes Association in the format Continuing Education via Copyright Clearance Center.

agonists are associated with gastrointestinal adverse effects that, though temporary in nature, must be discussed with patients and can be modified by gradual dose titration. In addition, GLP1 receptor agonists are associated with significant and sustained weight loss, whereas DPP-4 inhibitors tend to be weight neutral. Both classes of agents are associated with a low risk of hypoglycemia, unless used with insulin or insulin secretagogues, in which case the dose adjustment of the latter might need to be made.

\section{Summary}

Management of recent-onset T2DM presents the osteopathic physician with the opportunity to intervene early and assertively by interacting with patients on lifestyle interventions and the use of adequate pharmacotherapy. Such man- 


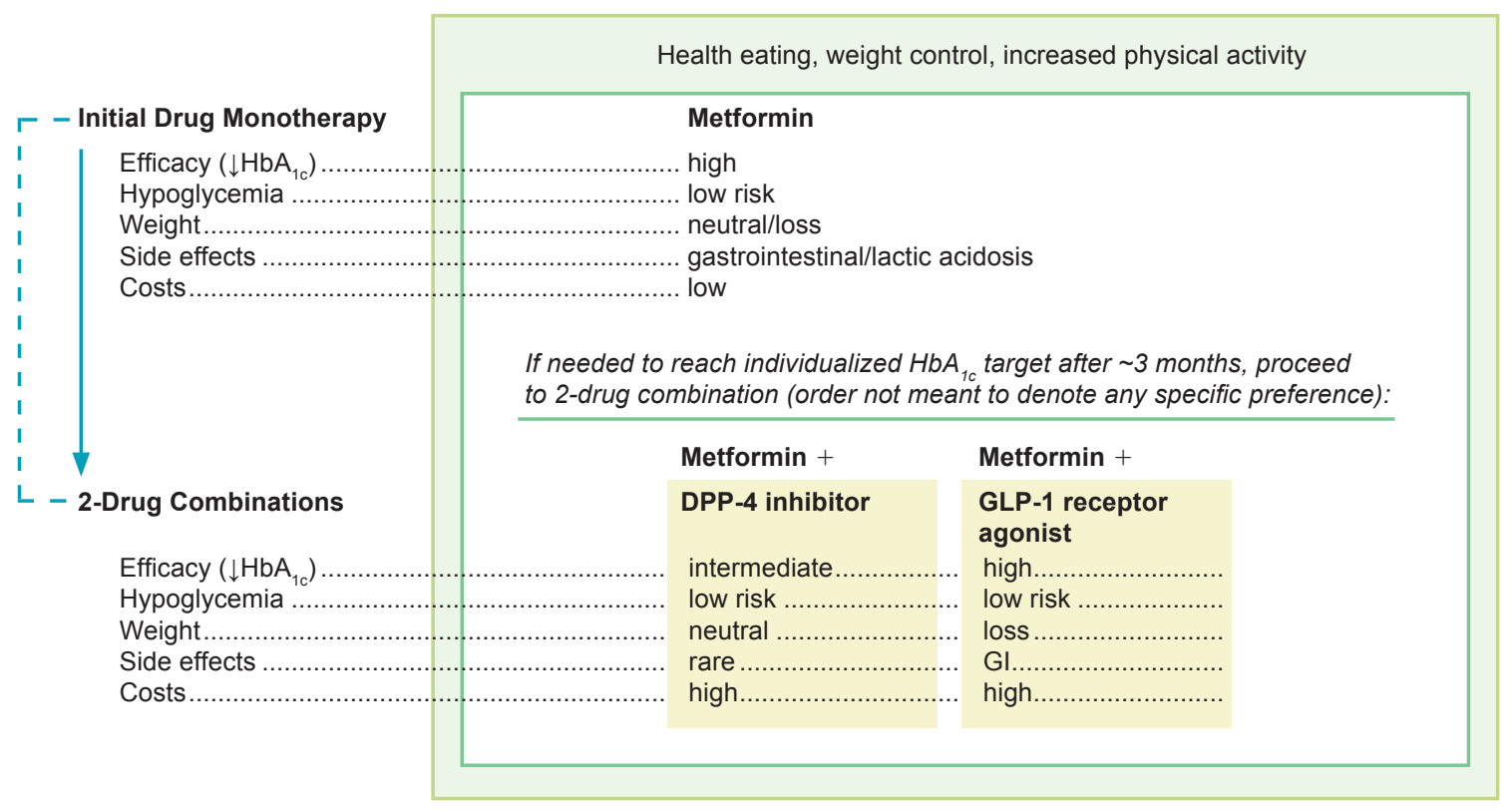

Figure 5.

Algorithm for patients when the goal is to avoid weight gain..$^{13}$ Source: Diabetes: a journal of the American Diabetes Association by American Diabetes Association; Stanford University. Reproduced with permission of the American Diabetes Association in the format Continuing Education via Copyright Clearance Center.

agement includes pharmacotherapy at the time of diagnosis with intensification as needed if glycemic goals are not met within 3 months of an adequate drug trial. Setting treatment goals with patients and discussing how these goals relate to diabetes-related complications is important.

A comprehensive approach to diabetes care now encompasses more than a gluco-centric approach to care. Polypharmacy and addressing the multifactoral nature of T2DM may be warranted even in the early stages of T2DM. Agents that have beneficial non-glycemic effects on $\beta$-cell function, weight, and hypoglycemia risk, such as the incretin-based therapies, may be especially useful tools for osteopathic physicians. However, they must also recognize that adverse effects and medication-related risk influence patient treatment choices and adherence rates.

\section{Acknowledgment}

The medical writing assistance

of Kate Mann, PharmD, from

E\&S MedEd Group, Inc, is gratefully acknowledged.

\section{References}

1. National Diabetes Fact Sheet. Centers for Disease Control and Prevention web site. 2011. http://www.cdc.gov/diabetes/pubs/factsheet11. htm. Accessed January 30, 2014

2. Dornhorst A, Merrin PK. Primary, secondary and tertiary prevention of non-insulindependent diabetes. Postgrad Med J. 1994;70(826):529-535.

3. Sherwin RS, Anderson RM, Buse JB, et al; American Diabetes Association; National Institute of Diabetes and Digestive and Kidney Diseases. Prevention or delay of type 2 diabetes. Diabetes Care. 2004;27 suppl 1:S47-S54.

4. Defronzo RA. From the triumvirate to the ominous octet: a new paradigm for the treatment of type 2 diabetes mellitus [Banting Lecture]. Diabetes. 2009;58(4):773-795. doi:10.2337/db09-9028.

5. Donath MY, Ehses JA, Maedler K, et al. Mechanisms of $\beta$-cell death in type 2 diabetes. Diabetes. 2005;54(suppl 2):S108-S113.

6. Kahn SE, Haffner SM, Heise MA, et al; $\beta$ Study Group. Glycemic durability of rosiglitazone, metformin, or glyburide monotherapy. N Engl J Med. 2006;355(23):2427-2443.

7. Wright EE Jr, Stonehouse AH, Cuddihy RM. In support of an early polypharmacy approach to the treatment of type 2 diabetes. Diabetes Obes Metab. 2010;12(11):929-940. doi:10.1111/j.1463-1326.2010.01255.x.

8. Fong DS, Aiello L, Gardner TW, et al; American Diabetes Association. Retinopathy in diabetes. Diabetes Care. 2004;27 suppl 1:S84-S87.

9. Stratton IM, Adler AI, Neil HA, et al. Association of glycaemia with macrovascular and microvascular complications of type 2 diabetes (UKPDS 35): prospective observational study. BMJ. 2000;321(7258):405-412. 
10. Chalmers J, Cooper ME. UKPDS and the legacy effect. N Engl J Med. 2008;359(15):1618-1620. doi:10.1056/NEJMe0807625.

11. Murray P, Chune GW, Raghavan VA. Legacy effects from DCCT and UKPDS: what they mean and implications for future diabetes trials. Curr Atheroscler Rep. 2010;12(6):432-439. doi:10.1007/s11883-010-0128-1.

12. Brown JB, Conner C, Nichols GA. Secondary failure of metformin monotherapy in clinical practice [published online December 26, 2009]. Diabetes Care. Mar 2010;33(3):501-506. doi:10.2337/dc09-1749.

13. Inzucchi SE, Bergenstal RM, Buse JB et al. Management of hyperglycemia in type 2 diabetes: a patient-centered approach—position statement of the American Diabetes Association (ADA) and the European Association for the Study of Diabetes (EASD) [published online April 19, 2012] [published correction appears in Diabetes Care. 2013;36(2):490]. Diabetes Care. 2012;35(6):1364-1379. doi:10.2337/dc12-0413.

14. Garber AJ, Abrahamson MJ, Barzilay JI, et al. American Association of Clinical Endocrinologists' comprehensive diabetes management algorithm 2013 consensus statement-executive summary. Endocr Pract. 2013;19(3):536-557. doi:10.4158/EP13176.CS

15. American Diabetes Association. Standards of medical care in diabetes-2014. Diabetes Care. 2014;37 suppl 1:S14-S80. doi:10.2337/dc14-S014.

16. Nathan DM, Buse JB, Davidson MB, et al. Medical management of hyperglycemia in type 2 diabetes: a consensus algorithm for the initiation and adjustment of therapy: a consensus statement of the American Diabetes Association and the European Association for the Study of Diabetes [published online October 22, 2008]. Diabetes Care. 2009;32(1):193-203. doi:10.2337/dc08-9025.

17. Raskin P. Sodium-glucose cotransporter inhibition: therapeutic potential for the treatment of type 2 diabetes mellitus. Diabetes Metab Res Rev. 2013;29(5): 347-356. doi:10.1002/dmrr.2403.

18. Garcia-Pérez LE, Alvarez M, Dilla T, Gil-Guillén $\mathrm{V}$, Orozco-Beltrán D. Adherence to therapies in patients with type 2 diabetes [published online August 30, 2013]. Diabetes Ther. 2013;4(2) 175-194. doi:10.1007/s13300-013-0034-y.

19. Cernea S. The role of incretin therapy at different stages of diabetes [published online November 10, 2011]. Rev Diabet Stud. 2011;8(3):323-338. doi:10.1900/RDS.2011.8.323.

20. Vilsboll T, Garber AJ. Non-glycaemic effects mediated via GLP-1 receptor agonists and the potential for exploiting these for therapeutic benefit: focus on liraglutide. Diabetes Obes Metab. 2012;14 suppl 2:41-49. doi:10.1111/j.1463-1326.2012.01579.x.
21. Garber AJ. Incretin effects on $\beta$-cell function, replication, and mass: the human perspective. Diabetes Care. 2011;34 suppl 2:S258-S263. doi: $10.2337 / \mathrm{dc} 11-\mathrm{s} 230$.

22. Aschner P, Katzeff HL, Guo H, et al; Sitagliptin Study 049 Group. Efficacy and safety of monotherapy of sitagliptin compared with metformin in patients with type 2 diabetes [published online November 25, 2009]. Diabetes Obes Metab. 2010;12(3):252-261. doi: 10.1111/j.1463-1326.2009.01187.x.

23. Aschner P, Kipnes MS, Lunceford JK, et al; Sitagliptin Study 021 Group. Effect of the dipeptidyl peptidase-4 inhibitor sitagliptin as monotherapy on glycemic control in patients with type 2 diabetes. Diabetes Care. 2006;29(12):2632-2637.

24. Nonaka K, Kakikawa T, Sato A, et al. Efficacy and safety of sitagliptin monotherapy in Japanese patients with type 2 diabetes. Diabetes Res Clin Pract. 2008;79(2):291-298.

25. Raz I, Hanefeld M, Xu L, et al; Sitagliptin Study 023 Group. Efficacy and safety of the dipeptidyl peptidase-4 inhibitor sitagliptin as monotherapy in patients with type 2 diabetes mellitus. Diabetologia. 2006;49(11):2564-2571

26. Rosenstock J, Sankoh S, List JF. Glucoselowering activity of the dipeptidyl peptidase-4 inhibitor saxagliptin in drug-naive patients with type 2 diabetes [published online March 18, 2008]. Diabetes Obes Metab. 2008;10(5): 376-386. doi:10.1111/j.1463-1326.2008.00876.x.

27. Rosenstock J, Aguilar-Salinas C, Klein E, Nepal S, List J, Chen R; CV181-011 Study Investigators. Effect of saxagliptin monotherapy in treatment-naive patients with type 2 diabetes. Curr Med Res Opin. 2009;25(10):2401-2411. doi:10.1185/03007990903178735.

28. Russell-Jones D, Cuddihy RM, Hanefeld M, et al; DURATION-4 Study Group. Efficacy and safety of exenatide once weekly versus metformin, pioglitazone, and sitagliptin used as monotherapy in drug-naive patients with type 2 diabetes (DURATION-4): a 26-week double-blind study [published online December 30, 2011]. Diabetes Care. 2012;35(2):252-258. doi:10.2337/dc11-1107.

29. Moretto TJ, Milton DR, Ridge TD, et al. Efficacy and tolerability of exenatide monotherapy over 24 weeks in antidiabetic drug-naive patients with type 2 diabetes: a randomized, double-blind, placebo-controlled, parallel-group study [published correction appears in Clin Ther. 2008;30(10):1937]. Clin Ther. 2008;30(8):1448-1460. doi:10.1016/j.clinthera.2008.08.006.

30. Yuan GH, Song WL, Huang YY, Guo XH, Gao Y. Efficacy and tolerability of exenatide monotherapy in obese patients with newly diagnosed type 2 diabetes: a randomized,
26 weeks metformin-controlled, parallel-group study. Chin Med J (Engl). 2012;125(15):2677-2681.

31. Vilsboll T, Zdravkovic M, Le-Thi T, et al. Liraglutide, a long-acting human glucagonlike peptide-1 analog, given as monotherapy significantly improves glycemic control and lowers body weight without risk of hypoglycemia in patients with type 2 diabetes. Diabetes Care. 2007;30(6):1608-1610.

32. Garber A, Henry R, Ratner R, et al; LEAD-3 (Mono) Study Group. Liraglutide versus glimepiride monotherapy for type 2 diabetes (LEAD-3 Mono): a randomised, 52-week, phase III, double-blind, paralleltreatment trial [published September 24, 2008]. Lancet. 2009;373(9662):473-481. doi:10.1016/S0140-6736(08)61246-5.

33. Jendle J, Nauck MA, Matthews DR, et al; LEAD-2 and LEAD-3 Study Groups. Weight loss with liraglutide, a once-daily human glucagon-like peptide- 1 analogue for type 2 diabetes treatment as monotherapy or added to metformin, is primarily as a result of a reduction in fat tissue. Diabetes Obes Metab. 2009;11(12):1163-1172. doi: 10.1111/j.14631326.2009.01158.x

34. Seino $Y$, Rasmussen MF, Nishida T, Kaku K. Efficacy and safety of the oncedaily human GLP-1 analogue, liraglutide, vs glibenclamide monotherapy in Japanese patients with type 2 diabetes. Curr Med Res Opin. 2010;26(5):1013-1022. doi:10.1185/03007991003672551.

35. Bode BW, Testa MA, Magwire M, et al; LEAD-3 Study Group. Patient-reported outcomes following treatment with the human GLP-1 analogue liraglutide or glimepiride in monotherapy: results from a randomized controlled trial in patients with type 2 diabetes. Diabetes Obes Metab. 2010;12(7):604-612. doi:10.1111/j.1463-1326.2010.01196.x.

36. Garber A, Henry RR, Ratner R, et al; Hale P, Chang CT, Bode B; LEAD-3 (Mono) Study Group. Liraglutide, a once-daily human glucagon-like peptide 1 analogue, provides sustained improvements $i$ n glycaemic control and weight for 2 years as monotherapy compared with glimepiride in patients with type 2 diabetes. Diabetes Obes Metab. 2011;13(4):348-356. doi:10.1111/j.1463-1326.2010.01356.x.

๑) 2014 American Osteopathic Association 